\title{
SACRIfices, Self-Defense, ANd Victim Relations
}

\author{
THOMAS NADELHOFFER
}

THIS IS A PENULTIMATE DRAFT. THE PAPER IS UNDER REVIEW.

\begin{abstract}
:
In this paper, I first survey the history of the trolley problem from Philippa Foot to Judith Jarvis Thomson. I then canvass Thomson's earlier attempts to solve the problem before discussing her more recent about-face. Because I find her latest solution (or attempted dissolution) to be problematic, I revisit Thomson's earlier work on self-defense in an effort to find an alternative route to a solution. By switching the vantage point from the actors to the victims, I try to reveal an element of the cases that has hitherto escaped notice. On my view, to the extent that the victims being sacrificed have a legitimate claim to selfdefense, this suggests that their being sacrificed in the name of the greater good is impermissible after all. So, while it would be heroic if they engaged in altruistic selfsacrifice, it is well within their rights to resist being sacrificed. If I am right about this, it suggests that negative rights are weightier than positive rights-much as Thomson herself came to believe. If this is right, then the trolley problem was much ado about nothing. The entire enterprise was predicated on the mistaken belief that it is permissible for the bystander to kill the one in order to save the five. Once that case is seen aright, the rest of our intuitions fall into their proper place.
\end{abstract}

\section{INTRODUCTION}

When Philippa Foot introduced a handful of thought experiments forty years ago in a landmark paper about abortion and the doctrine of double effect, she couldn't have foreseen that her work would eventually lead to a vast literature that spans first-order moral philosophy, meta-ethics, and empirical moral psychology (Foot 1967). ${ }^{1}$ Years later, in a series of equally groundbreaking papers, Judith Jarvis Thomson picked up where Foot

\footnotetext{
${ }^{1}$ To get a sense for just how much work has been done on the trolley problem, consider the following: If you do a search on Google Scholar for "the trolley problem," the search returns more than 3,000 references. See Edmonds (2013) for a broad overview of the trolley problem and all its variant thought experiments as well as biographical sketches of some of the main figures who have contributed to the literature.
} 
left off and the so-called "trolley problem" was officially born (Thomson 1976; 1985;

1990; 1991). ${ }^{2}$ A laundry list of the world's leading moral philosophers and moral psychologists have subsequently made their own contributions to the debate concerning whether and when it is permissible to knowingly and intentionally sacrifice a life (or lives) in order to save more lives or even to save one's own life in the case of self-defensewhich are issues that go straight to the heart of the trolley problem. Given that the trolley problem makes it easy to highlight some important issues in ethics, psychology, public policy, and the law, it is perhaps unsurprising that so much ink has been spilled on its behalf in so many areas of inquiry. ${ }^{3}$

As someone who has already contributed to the empirical literature on the moral psychology of the trolley problem (XXXX), my primary goal in the present paper is to shift gears in order to make what I hope will be a contribution to the literature on the moral philosophy of the trolley problem. Consequently, my first order of business will be to review some of the key developments in the literature-with a particular focus on the

\footnotetext{
${ }^{2}$ There is even some debate when it comes to what counts as the trolley problem. I will address this taxonomic issue in the coming pages.

${ }^{3}$ Not everyone welcomes the attention the trolley problem has received. Barbara Fried, for instance, mockingly refers to this area of research as "trolleyology" $(2012,506)$ and she claims it is at best a "moral sideshow" $(2012,506)$ that encourages us mistakenly focus on the "freaks and sports of human interaction" (2012, 509). On her view, "trolleyologists" obsess unhealthily about cases which lack "contextual information that in real life changes the moral complexion of tragic choices" $(2012,509)$. Similar criticisms (albeit with perhaps less derision) can be found in Hurka (2016) and Wood (2011). For instance, Tom Hurka wonders just how much weight we should give to intuitions we have in response to highly abstract thought experiments in contrast with the intuitions we have in response to more realistic scenarios $(2016,139)$. Similarly, Allen Wood suggests that "most of the situations described in trolley problems are highly unlikely to occur in real life and the situations are described in ways that are so impoverished as to be downright cartoonish" $(2011,69)$. Needless to say, addressing these pressing meta-ethical concerns is beyond the scope of the present essay (which is not to say these concerns are unimportant). Defending the first-order work on the trolley problem is a task for another day. It is enough just to make a noteworthy contribution to the sprawling literature on the trolley problem without, at the same time, having to defend the entire enterprise from its meta-ethical critics.
} 
seminal work done by Foot and Thomson (§1). At this stage, I will discuss several of the main thought experiments that have been introduced along the way. I will also talk about Thomson's early attempts to solve the trolley problem and the shortcomings of these attempts-shortcomings that eventually led her to completely change her mind about her earlier claims concerning whether and when it's permissible to sacrifice one stranger in order to save five other strangers. As we'll see in $\S 2$, Thomson (2008) contains a completely novel approach when it comes to how to answer the aforementioned question about the moral permissibility of certain sacrifices. Indeed, Thomson does a complete about-face-concluding that what she earlier coined as the trolley problem turns out to be a "non-problem" after all (2008). In short, she suggests that once we look at the cases in the right light, we ought not have conflicting moral intuitions-and if there are no conflicting intuitions to be explained (or to be explained away), there is, technically speaking, no problem left to be addressed. On her most recent view, Thomson claims to have devised a way to finally lay the (non)problem about trolleys and human sacrifice to rest.

While I will ultimately agree with Thomson's most recent assessment that the trolley problem is actually a non-problem at the end of the day-since I, too, think that once we look at the main thought experiments in the right light, it ought to resolve our conflicting intuitions - I will also argue that her particular argument to this effect is problematic and unsatisfying. I will then go on to claim that Thomson already had the requisite argumentative tools at her disposal in her earlier work to devise a more compelling way of laying the trolley problem to rest. So, having raised some concerns 
about Thomson's most recent approach to the trolley problem (or the non-problem, as the case may be), I will sketch a different route to the same conclusion based, in part, on some of Thomson's own related work on sacrifice and self-defense-which is a literature that both runs parallel to (in some places) and overlaps with (in other places) the trolley problem (§3).

Having covered some of the relevant literature on self-defense-including Thomson's own contributions (1991) - I will then revisit two of the main cases from the early literature that led to the original formulation of the trolley problem: (a) the Bystander at the Switch (BAS), and (b) the Bystander on the Footbridge (BOF). These cases will be revisited and viewed specifically through the lens of self-defense. More importantly, they will also be viewed from the vantage point not of the respective bystanders-who have been the traditional focus of the entire discussion-but rather from the vantage point of the individuals who stand to be harmed by the bystanders' decisions and actions. By looking at the trolley problem from the viewpoint of the people being saved or sacrificed rather than from the viewpoint of the people who will be doing the saving and sacrificing, I will suggest that this ought to change our intuitions concerning whether and when it's permissible to sacrifice one in order to save others.

My overarching goal in this paper is two-fold: First, I will argue that when we view some of the classic thought experiments on the trolley problem from the perspective of the individuals whose lives are at stake rather than from the point of view of the bystanders, we find that the cases are more symmetrical than Thomson and others have acknowledged. Second, I will argue that if a bystander decides to kill one person in order 
to save five-either by diverting a trolley or by pushing a large man off a footbridge - the person who would be killed has a legitimate right to self-defense. This, in turn, suggests that the person diverting the trolley is doing something impermissible. Looking at the trolley problem against the backdrop of self-defense not only brings to the surface important issues that need to be considered before we reach any definitive conclusions concerning how best to solve (or dissolve) the trolley problem, it also highlights a tension that exists more generally between the permissibility conditions for self-defense and the permissibility conditions for sacrificing people against their wishes in the name of the greater good.

\section{§1: Setting the Stage}

Foot begins her investigations in "The Problem of Abortion and the Doctrine of Double Effect" by noting the difficulty of ascertaining what it is permissible to do under circumstances where human interests conflict with one another (1967). Her guiding question in addressing this issue is whether or not the doctrine of double effect is useful in resolving the kinds of moral conflicts of interest that she has in mind. According to Foot, the doctrine of double effect is "based on the distinction between what a man foresees as a result of his voluntary behavior and what, in the strict sense, he intended. He intends in the strict sense both those things he aims at as ends and those that he aims at as a means to his ends" $(1967,1)$. On this view, "sometimes it makes a difference to the permissibility of an action involving harm to others that this harm, although foreseen, is not part of the agent's direct intention" $(1967,3)$. Having sketched out what she has in 
mind in this regard, Foot introduces the following thought experiments-which could rightly be described as the first shots across the moral bow in what would eventually become the trolley problem: ${ }^{4}$

\section{The Tram Driver and Diversion (Tram Driver, for short):}

A pilot whose airplane is about to crash is deciding whether to steer from a more to a less inhabited area. To make the parallel as clear as possible it may rather be supposed that he is the driver of a runaway tram which he can only steer from one narrow track onto another; five men are working on one track and one man is working on the other; anyone on the track he enters is bound to be killed (Foot 1967, 3).

\section{The Doctor's Short Supply Passive (Short Supply Allow, for short): ${ }^{5}$}

We are about to give a patient who needs to save his life a massive dose of a certain drug in short supply. There arrive, however, five other patients each of whom could be saved by one-fifth of that dose. We say with regret that we cannot spare our whole supply of the drug for a single patient, just as we should say that we could not spare the whole resources of a ward for one dangerously ill individual when ambulances arrive bringing victims from a multiple crash (Foot 1967, 4).

\section{The Doctor's Short Supply Active (Short Supply Kill, for short):}

We can suppose, similarly, that several dangerously ill people can be saved only if we kill a certain individual and make a serum from his dead body (Foot 1967, 4).

\footnotetext{
${ }^{4}$ The first two thought experiments in Foot (1967) were: (a) Spelunking Gone Wrong: [Imagine that there is] a fat man stuck in the mouth of the cave. A party of potholers has imprudently allowed the fat man to lead them as they make their way out of the cave, and he gets stuck, trapping the others behind them...Imagine there are rising waters and the potholers find some dynamite. May the potholers use the dynamite to kill the fat man, thereby liberating themselves from the cave? (Foot 1967, 2); and (b) Executing the Innocent: Suppose that a judge or magistrate is faced with rioters demanding that a culprit be found for a certain crime and threatening otherwise to take their own bloody revenge on a particular section of the community. The real culprit being unknown, the judge sees himself as able to prevent bloodshed only by framing some innocent person and having him executed (Foot 1967, 3). While I am not going to discuss these two cases, the analysis I offer at the end covers them as well. So, I thought it was worth at least including them here in a footnote for good measure.

${ }^{5}$ Foot's Short Supply has two variations: In the first version, which I am calling Short Supply Allow the doctor allows one to die in order to save five others. In the second version, which I am calling Short Supply Kill, the doctor kills one in order to save five. The importance of this distinction will be clear once we get to Thomson's response to Foot.
} 
With these thought experiments, the seeds for the trolley problem were formally sewn. What they are supposed to highlight is that we sometimes find it morally permissible to sacrifice one individual to save more lives (e.g., the innocent person run down by the tram driver) and yet at other times we find this kind of sacrifice to be impermissible (e.g., the innocent person who is killed to make the serum). It is our purported conflicting intuitions in response to these kinds of cases that give rise to the problem under investigation. After all, it stands to reason that we ought to be able to offer reasons that explain (or explain away) our intuitional disarray. What it seems we need, in the wake of Foot's thought experiments, is a principled moral account of human sacrifice which best captures our disparate judgments in response to cases that share some surface similarities.

It obviously can't be a brute numbers game where we simply tally up the lives saved overall and side with whichever action yields the largest number, for if that kind of consequentialist calculus explained our intuitions, these intuitions would be uniform across the cases (which Foot believes they are not). After all, in every case, a net four lives are saved by sacrificing the one. So, this fact alone can't do any explanatory or justificatory work. What about the doctrine of double effect? Can that help explain our conflicting intuitions? Foot's not so sure that it can. As she says, "my conclusion is that the distinction between direct and oblique intention plays only a quite subsidiary role in determining what we say in these cases" $(1967,6) .^{6}$

\footnotetext{
${ }^{6}$ The distinction between direct and oblique intentions can be found, among other places, in Bentham's work on action theory (1780/1996, 86-87). When I both knowingly and intentionally perform an action, I am said to have acted on a direct intention. If I have a direct intention to $x$, then $x$-ing is my goal, that is, it
} 
Having suggested that there is not much mileage to be gotten from the doctrine of double effect, Foot goes on to suggest that the difference between "the duty to avoid injury" and the "duty to provide aid" might help shed light on the moral landscape she has sketched $(1967,5)$. To clarify what she has in mind, she introduces the distinction between positive and negative duties that had been earlier formulated in Salmond (1913): A positive right corresponds to a positive duty and is a right that he on whom the duty lies shall do some positive act on behalf of the person entitled. A negative right corresponds to a negative duty and is a right that the person bound shall refrain from some act which would operate to the prejudice of the person entitled. The former is a right to be positively benefited; the latter is merely a right not to be harmed (283).

Armed with this distinction, Foot revisits the cases she introduced earlier. And she suggests that the difference between positive and negative rights can, indeed, help shed light on our conflicting intuitions. Take the two versions of Short Supply-namely, the doctor who withholds treatment from the one in order to save the five and the doctor who actively kills the one in order to save the five. According to Foot, it is permissible for the doctor to withhold treatment in Short Supply Allow but it is impermissible for the doctor to kill the one in Short Supply Kill (Foot 1967, 5). Here again, this can't be explained in terms of net lives saved-since the same number of lives are saved in each case. Instead, Foot suggests that in Short Supply Allow, the doctor is satisfying his positive duty

\footnotetext{
is what I am trying to bring about. On the other hand, when I merely knowingly bring about a foreseen but undesired side effect, I am said to have acted on an oblique intention. If I have an oblique intention to $x, x-$ ing is a foreseeable but undesired consequence of my primary goal of intentionally $y$-ing, that is, $x$ is not something I am trying to bring about.
} 
to provide aid (without at the same time violating the negative duty to avoid causing injury). In Short Supply Kill, on the other hand, while the doctor there, too, is living up to his duty to provide aid, in doing so he is failing to live up to his negative duty not to cause injury. Foot also thinks the distinction between positive and negative duties helps explain our intuitions in Tram Driver (Foot 1967, 5). After all, in that case, the driver has two conflicting negative duties - he has a negative duty to avoid harming the five and he has a negative duty to avoid harming the one. Given that he will violate a negative duty no matter he does, Foot suggests that it is permissible for the driver to proceed in such a way that causes as little harm as possible. ${ }^{7}$

Having introduced the distinction between positive and negative rights and having explained how this distinction might help shed light on our conflicting intuitions about the series of thought experiments she introduced, Foot brings her paper to a close. Several years later, Judith Jarvis Thomson picked up the torch that had been lit by Foot and ran with it. In a series of papers, she further problematized what she would later call "Ms. Foot's Problem"-namely, the problem of explaining our conflicting intuitions in Tram Driver and Short Supply Kill. ${ }^{8}$ To highlight the fact that the appeal to positive and negative

\footnotetext{
${ }^{7}$ Notice that here, too, the doctrine of double effect, by itself, won't give us any practical guidance because the tram driver will be acting on a direct intention no matter which choice he makes. He finds himself in a moral dilemma where he has a choice-intentionally decide to kill the five or intentionally decide to kill the one. There is no third way. As such, if we want to explain why we think the tram driver should sacrifice the one, we will have to appeal to something above and beyond the doctrine of double effect.

${ }^{8}$ Thomson changed her terminology over the years. In Thomson (1976), she called our conflicting intuitions in Tram Driver and Short Supply Killing "the trolley problem" (206). But she would later call this particular problem instead "Ms. Foot's Problem" (Thomson 1985, 1396). At that point, she claimed that the trolley problem pertains to our conflicting intuitions in Bystander at the Switch and Short Supply Killing (1985, 1401). Later still, Thomson would finally come to identify the trolley problem with our conflicting intuitions in Bystander at the Switch and Bystander on the Footbridge $(2008,363)$. I will be following Thomson's most recent terminology in this paper. While all of the cases that have been developed over the years fall under the umbrella of the trolley problem, broadly construed, the specific conflict I will be most interested in is
} 
rights won't help explain our conflicting intuitions in response to a broader range of cases,

Thomson first provides her own versions of Foot's Short Supply Kill and Tram Driver (1976, 206) - which Thomson prefers instead to call Trolley Driver instead. It is this subtle change

in terminology which explains why we presently call the debate about the permissibility (or lack thereof) of human sacrifice the trolley problem rather than the tram problem $!^{9}$ That said, having reintroduced Foot's cases, Thomson proceeds to introduce two thoughts experiments of her own ${ }^{10}$ :

\section{Bystander at the Switch (BAS, for short):}

Suppose that you are walking next to a trolley track when you suddenly realize that there is a runaway trolley coming in your direction. It is clear that if the trolley continues on its present path, it will kill five track workmen who are repairing the track up ahead. However, you notice that there is a switch immediately in front of you that you could hit that would turn the trolley onto a side track off to the right. Unfortunately, there is one workman on the side track who would certainly be killed if you intervene by hitting the switch and diverting the train.

\section{Bystander on the Footbridge (BOF, for short):}

Suppose that you are standing on a footbridge that transcends over a trolley track when you suddenly realize that there is a runaway trolley coming in your direction. It is clear that if the trolley continues on its present path, it will kill five track workmen who are repairing the track up ahead. Luckily, you are an expert on trolleys, so you know that the

the tension between our intuitions about BAS and BOF. That said, some "cousin cases," to borrow a useful phrase from Francis Kamm, will invariably crop up along the way $(2016,21)$.

${ }^{9}$ Much later, Thomson chalks this up to a cultural difference coupled with an aesthetic preference. As she says, "since trams are trolleys on this side of the Atlantic, I called this "the trolley problem." (Besides, that is more euphonious than "the tram problem)" (2008, 363).

${ }^{10}$ For both of these thought experiments, I am not using Thomson's direct wording or even the same labels-e.g., what I call "Bystander on the Footbridge" she calls "Fat Man". In Thomson (1976), the details for these thought experiments were minimal and a bit sketchy. For the first version of Bystander at the Switch, see Thomson $(1976,207)$ and for the first version of Bystander on the Footbridge, see Thomson $(1976,216)$. She developed them in somewhat more detail in Thomson (1985). But because these are going to end up being the primary focus of my investigation-given that these two cases eventually became the core of what she had in mind when she talked of the trolley problem-it's important that these two thought experiments are clearly defined. I presume Thomson would not object to any aspect of my wording. I have tried very carefully to ensure that my versions capture all of the salient features of the originals. 
best way to stop a runaway trolley is to drop something really heavy in its path. And it just so happens that there is a very large man standing next to you on the footbridge who is leaning over the railing watching the trolley as it rapidly approaches. You realize that if you just give him a shove, he will fall onto the track below. This means that you can use his body to stop the trolley from killing the five workmen.

Before we look at Thomson's contrastive analysis of BAS and BOF, it is illustrative to briefly take a look at how she views these thought experiments in relation to Foot's earlier examples. For starters, Thomson revisits Foot's attempted solution to the problem introduced by the contrast between Tram Driver and Short Supply Kill. According to Thomson, Foot's approach on this front is "simple, straightforward, and very attractive" $(1985,1396)$. Moreover, Thomson suggests that Foot's appeal to positive and negative duties can be fruitfully viewed through the lens of the killing vs. letting die distinction. First, on this approach, killing one is worse than allowing five to die-which is why Foot thought it was impermissible for the doctor in Short Supply Kill to sacrifice one in order to save five. Second, killing five is worse that killing one-which is why Foot thinks it's permissible for the tram driver to sacrifice the one to save the five.

However, while Thomson thinks that the killing vs. allowing to die distinction may help explain our intuitions in some of Foot's cases, she thinks "there is good reason to think that this problem is not easily solved as that" $(1985,1397)$. To back up this claim, she contrasts our purported intuitions in cases like Short Supply Kill with our intuitions in both BAS and BOF. In Short Supply Kill, we find it impermissible to sacrifice the one. We have a similar judgment in BOF. In both cases, we might be tempted to explain our unified intuitions in terms of the aforementioned killing vs. allowing to die distinction given that in each case, in order to save five lives, you have to kill one person-which violates the 
rule against killing one in order to save five. On this interpretation, the killing vs. allowing to die distinction rules out precisely the kind of sacrifices that are up for debate in Short Supply Kill and BOF.

But Thomson thinks this is incomplete. On her view, BAS overturns this proverbial moral applecart. After all, Thomson thinks that our intuitions suggest that it is permissible to sacrifice the one in order to save the five in BAS even though the bystander would be killing one rather than allowing five to die. ${ }^{11}$ If this is correct, then the killing vs. allowing to die distinction (as well as Foot's earlier distinction between positive duties and negative duties) cannot explain all of our salient intuitions-e.g., if BAS reveals the killing vs. allowing to distinction to be false, then this distinction can't be used to explain cases like Short Supply Killing and BOF. According to Thomson:

The thesis that killing is worse than letting die cannot be used in any simple, mechanical way to yield conclusions about abortion, euthanasia, and the distribution of scarce medical resources. The cases have to be looked at individually...there are circumstances in which-even if it is true that killing is worse than letting die-one may [permissibly] choose to kill instead of letting die. (1976, 217)

So, at this point, Thomson's focus turns away from Foot's earlier cases and analyses and she directs her focus on the two main cases she is considering-namely, BAS and BOF. To recapitulate, while Thomson believes that it is impermissible for the bystander to push the large man off the footbridge in BOF $(1991,1409)$, she thinks it is permissible for the

\footnotetext{
${ }^{11}$ Thomson also distinguishes between Tram Driver and BAS (Thomson 1985, 1398). In the former case, Thomson suggests the driver would be killing the five if he doesn't divert the trolley just as he would be killing the one in the event he diverts it. In BAS, on the other hand, Thompson claims that if the bystander decides not to hit the switch, he will merely be allowing the five to die whereas if he hits the switch, he will be killing the one. The fact that we think that trolley driver may divert the trolley onto the one suggests that the killing vs. allowing die distinction isn't up the present task.
} 
bystander to hit the switch in order to divert the train onto the side track in BAS (1991, 1395). ${ }^{12}$ On her view, "if you see something, a trolley, a boulder, an avalanche, heading towards five, and you can deflect it onto one, it really does seem that-other things being equal-it would be permissible for you to take charge, take responsibility, and deflect the thing" $(1985,1397-1398)$. With that in mind, what is it about BAS that makes intervention permissible that does not at the same time make it permissible for the bystander to intervene in BOF? Thomson eventually came to call this particular set of conflicting intuitions the "trolley problem" (Thomson 2008, 262-263). In this paper, I will be following suit.

Before we examine how Thomson attempts to address her conflicting intuitions, I

first want to highlight some features that BAS and BOF have in common:

1. Both cases involve bystanders who are not responsible for the events that are unfolding but who nevertheless have the ability to intervene in order to save five workmen.

2. Each bystander has a choice between passively allowing five to die and actively killing one.

3. There is no special bond that ties the bystanders to the other characters in the two respective thought experiments-e.g., family, friendship, romance, etc.

4. None of the workmen waive their general right to life just because they voluntarily perform a job that involves the risk of loss of life or limb.

5. The bystanders don't have any ill will towards the individuals whose lives they have decided to sacrifice nor do they owe any debts to them.

6. There is no salient moral difference between each of the five workmen, on the one hand, and the lone workman (or the large man), on the other hand.

7. Both of the bystanders would avoid killing anyone at all if they could-but as things stand, the only way for them to save five is to adopt a plan that involves sacrificing one.

\footnotetext{
${ }^{12}$ It is worth noting here that Thomson's conflicting intuitions when it comes to BAS and BOF have empirical support. As part of Mar Hauser's research involving the "Moral Sense Test"-which involved a survey of several thousand participants-while roughly $90 \%$ of participants thought it was permissible for the bystander to hit the switch in BAS, only $10 \%$ thought it was permissible for the bystander to push the large man in BOF $(2006,139)$.
} 
8. By intentionally hitting the switch (or pushing the large man), the bystander knowingly adopts a plan that will kill one person in order to save five others.

9. By knowingly adopting a plan that will kill one in order to save five, the bystander thereby violates a general right to life of the individual whose life she decides to sacrifice.

10. In both cases, the individuals whose lives the bystander decides to sacrifice do not waive their general right to life in the name of the greater good.

These are similarities that Thomson either explicitly does acknowledge or presumably would acknowledge if pressed to do so. In some sense, in making these details explicit, I am simply addressing a criticism Thomson made of some of the earlier cases (including her own)-namely, that "the cases were under-described, and what [was] supplied as filler was that the six on the track are on a par: that there was nothing further true of any of them which has a bearing on the question of whether or not it was permissible to turn the trolleys" $(1976,211)$.

Having made the requisite clarifications, I now hope it's clear that if Thomson wants to justify her earlier intuition that it is permissible for the bystander in BAS to hit the switch but that it impermissible for the bystander in BOF to push the large man off the bridge, she will need to identify a difference between the two scenarios that is robust enough to do the argumentative heavy lifting. We have already ruled out a brute calculus focused on the resultant body count. We have also ruled out the distinction between positive and negative duties and the killing vs. allowing to die distinction. ${ }^{13}$ What remains that could do the explanatory and justificatory work?

\footnotetext{
${ }^{13}$ Consider, for instance, the following remarks by Thomson: "If the bystander [in BAS] throws the switch, he causes the trolley to hit the one, and thus he kills the one. It is equally plain that if the bystander does not throw the switch, he does not cause the trolley to hit the five, he does not kill the five, he merely fails to save them-he lets them die" $(1985,1398)$. As such, Thomson thinks that the distinction between positive and negative duties as well as the distinction between killing and allowing to die can't help explain
} 
According to Thomson's earlier writings, in order to solve the trolley problem, we must focus on the notion of rights as it relates to the means-end relationship that exists between the bystanders and the individuals they would harm in their efforts to save the five. More specifically, she suggests that despite the fact that in both BAS and BOF the bystander wrongs the person whose life she sacrifices, only BOF involves a direct violation of someone's rights $(1985,1409)$. On this view, the means by which the bystander intervenes in order to save the five in BOF-namely, pushing the large man to his deathdirectly infringes upon the large man's right not to be killed, whereas the means by which the bystander intervenes to save the five in BAS-namely, hitting a switch and diverting the trolley-does not, in and of itself, amount to a direct infringement of the lone workman's rights. Thomson suggests that this difference purportedly explains why it is permissible for the bystander to intervene in BAS. Because the bystander in this case can maximize utility by saving the five without directly infringing upon the rights of the lone workman, her doing so is permissible (but not obligatory). Conversely, because the bystander in BOF would directly violate the rights of the large man, sacrificing him in the name of the greater good is impermissible.

But even if we agree with Thomson that in BAS the bystander doesn't directly violate the rights of the lone workman, it is clear that she nevertheless indirectly violates his rights. This is something that Thomson explicitly admits with the following remarks:

Suppose there weren't anybody on the straight track, and the bystander turned the trolley onto the right-hand track, thereby killing, the one, but not saving anybody, since nobody was at risk, and this nobody needed saving. Wouldn't that

our disparate intuitions whether we are talking about BAS vs. BOF or we're talking about Short Supply Allow or Short Supply Kill $(1985,1399)$. 
infringe a right of the one workman's, a right in the cluster of rights that he has in having a right to life? $(1985,1404)$

So, the issue is not whether the bystander violates the lone workman's rights-the issue is whether this particular rights violation is permissible. On Thomson's view:

There is some reason to think that the bystander will infringe the right of the one if he throws the switch, even though it is permissible for him to do so...The bystander made him pay with his life for the bystander's saving of the five. This consideration seems to me to lend some weight to the idea that the bystander did him a wrong-a wrong that is permissible to do him $(1985,1405)$.

But why should the directness of the violation be relevant where a person's general right not to be killed is concerned? Imagine you are the one being sacrificed and hence you're the one who is having your rights infringed upon. Would you care whether the infringement is indirect as opposed to direct? I suspect not. So why think the direct vs. indirect distinction can help with our intuitions about BAS and BOF? Given that Thomson eventually changed her mind when it comes to the permissibility of hitting the switch in BAS, perhaps we need not concern ourselves with whether her earlier focus on the purported importance of the relative directness or indirectness of rights violations when it comes to the permissibility of human sacrifice. Instead, we should turn our attention to what came to be Thomson's settled opinion about the trolley problem.

\section{§2: Thomson's Turnabout}

In 2008, inspired by the dissertation of one of her graduate students (Alexander Friedman), Thomson revisited the trolley problem with a fresh pair of eyes. The idea from Friedman that she found most intriguing was the suggestion that perhaps negative duties are weightier than positive duties after all. If true, it would follow that the common intuition that it is permissible for the bystander to hit the switch in BAS is wrong. And if 
we jettison this intuition, the trolley problem would be solved (or dissolved). After all, the crux of the problem is the task of explaining why the bystander can hit the switch in BAS but cannot push the large man in BOF. If it turns out that it is impermissible to hit the switch in BAS, then there are no conflicting intuitions to be explained. Instead, we are left with the view that in both cases, you cannot sacrifice the one in order to save the five because, ceteris paribus, killing is worse than letting die. Given that Thomson is now convinced that she was wrong to ever think that sacrificing the one is permissible in BAS, she now concludes that the trolley problem turns out to be a non-problem after all. On her view, once you see the cases aright, there is nothing left to be explained (or explained away).

The key, then, is for Thomson to justify her revised claim that you can't sacrifice the one in BAS (much like BOF). In defending her shifting opinion in this regard, she develops a new thought experiment:

\section{Bystander's Three Options (BTO):}

The switch available to this bystander can be thrown in two ways. If he throws it to the right, the trolley will turn on the spur of the track to the right, thereby killing one workman. If he throws it to the left, then the trolley will turn onto the spur of the track to the left. The bystander himself stands on that left-hand spur of track and will himself be killed if the trolley turns onto it. Or, of course, he can do nothing, letting five workmen die $(2008,364)$.

The bystander in BTO has three options: (a) he can do nothing, letting five die, (b) he can throw the switch to the right, killing the lone workman, or (c) he can throw the switch to the left, killing himself. Thomson's intuition is that it would be impermissible for the bystander to opt for (b) given the possibility of opting for (c). To the extent that the bystander is unwilling to sacrifice himself to save the five, he cannot thereby sacrifice 
someone else instead-forcing that person to pay a price the bystander is himself unwilling to pay. As Thomson says, "If he can throw the switch to the left and turn the trolley onto himself, how dare he throw the switch to the right and turn the trolley onto the one workman?" $(2008,364)$. If the bystander doesn't feel like dying, it's realistic to assume the lone workmen doesn't feel like dying either. So, to the extent that the bystander isn't willing to sacrifice himself, he isn't justified in sacrificing someone else. ${ }^{14}$

Thomson's argument partly hinges on the claim that neither the bystander nor the lone workmen are obligated to sacrifice themselves. On her view, a person "may let five die if the only permissible means he has of saving them is killing himself" $(2008,365)$. Indeed, she goes on to suggest that the altruistic desire or willingness to sacrifice oneself under these circumstances is morally suspect. As she says, "A willingness to give up one's life simply on learning that five others will live if and only if one dies is a sign of a serious moral defect in a person" $(2008,366)$. So, while Thomson thinks there are circumstances in which altruistic self-sacrifice is admirable-e.g., saving one's children-she thinks that in the context of complete strangers, this kind of sacrifice is as problematic as it is rare.

With these distinctions on board, Thomson revisits BAS. There, the bystander doesn't have the option of sacrificing himself. So, is sacrificing the lone workmen in his steed permissible? Thomson now says "no." Insofar as the bystander wouldn't be willing to be sacrificed himself if the roles were reversed, he can't thrust the grave burden upon

\footnotetext{
${ }^{14}$ There is an empirical literature that has grown out of Thomsons' BTO case. For instance, Huebner and Hauser (2011) found that folk intuitions clash with Thomson's own intuitions about altruistic self-sacrifice. Di Nucci (2013) provides compelling evidence that moral common sense may be closer to Thomson's view than initially thought.
} 
the lone workman - who presumably also doesn't consent to being sacrificed in this way. In short, the bystander doesn't have the right to impose altruistic self-sacrifice on the lone workmen given that (a) the bystander wouldn't altruistically sacrifice himself, and (b) the lone workman doesn't consent to being sacrificed. Thomson then suggests that even if the bystander in BAS would have been willing to sacrifice himself given the choice, he can't impose his misguided altruism on the lone workman.

In light of these considerations, Thomson concludes-contra her earlier work on the trolley problem - that it is impermissible for the bystander to hit the switch in BAS after all. In this respect, BAS turns out to be much like BOF and Short Supply Kill. If this is right, then the intuitional divide that served as the crucible of the trolley problem has been bridged. While you can permissibly kill one rather than kill five (Tram Driver) or allow one to die rather than allowing five to die (Short Supply Passive), you can't kill one to save five (BAS, BOF, BTO, Short Supply Kill). On this view, "A must let five die if saving them requires killing B" $(2008,367)$. Moreover, according to Thomson, much like Foot before her, the reason you can't kill one in order to save five is that negative duties are more stringent than positive duties. If this is correct, the trolley problem is a nonstarter.

But is Thomson right? Perhaps my biggest concern with her settled view is that it is predicated on the idea that altruistic self-sacrifice is morally problematic. After all, if it is morally acceptable to be willing to altruistically self-sacrifice then either the bystander or the lone workman might plausibly decide they are willing to sacrifice themselves in order to save five others. And while Thomson finds altruistic self-sacrifice in the name of strangers morally unbecoming, such sacrifices are commonly and plausibly viewed as 
heroic-whether it is a police officer, a fireman, or a Good Samaritan. Contrary to Thomson's assessment, altruistic self-sacrifice is often (and I would argue rightly) highly esteemed. While self-sacrifice in the context of strangers is clearly supererogatory rather the obligatory-which is why we view people who makes these sacrifices as heroes-it isn't as morally problematic as Thompson suggests. If a bystander did sacrifice himself in BTO or a lone workman did consent to being sacrificed in BAS, this wouldn't be a moral failure on their respective parts. Quite the contrary. Under these circumstances, selfsacrifice would be both extraordinary and laudable. So, to the extent that Thomson needs to deny all of this to make her revised argument work, this counts against her newfound strategy for solving (or dissolving) the trolley problem.

On Thomson's view, the impermissibility of turning the trolley in BAS flows from the fact that altruistic self-sacrifice is not a morally live option for either the bystander or the lone workman. It is the impermissibility of altruistic self-sacrifice that grounds the impermissibility of hitting the switch. After all, even if the bystander would have been improperly willing to hit the switch to sacrifice himself had that been a choice for him to make, he can't force this purportedly misguided decision onto the lone workmen-who Thomson assumes shouldn't be willing to engage in altruistic self-sacrifice. But once we allow that such sacrifices are not just permissible but admirable, this problematizes Thomson's attempted solution to the problem. To the extent that the lone workman might be a moral hero-which would make hitting the switch permissible-the blanket prohibition against hitting the switch won't do. Indeed, by refusing to hit the switch in this context, we are failing to maximize utility without thereby violating anyone's rights. 
All the worse for Thomson's turnabout-dependent as it is on a negative evaluation of altruistic self-sacrifice.

Rather than considering how Thomson might respond to my concerns on this front, I want to take a different tact. For I happen to think Thomson already had the conceptual tools to dissolve the trolley problem before she switched positions. On my view, Thomson's earlier work on self-defense already contained the seeds for a dissolution. So, what I would now like to do is revisit that earlier work. I will then make an important adjustment that enables us to bridge the gap between Thomson's earlier work on the trolley problem and her work on self-defense-namely, I will switch the vantage point from the bystanders to their potential victims. If I am right, Thomson already had the pieces in place to solve the trolley problem without appealing to the moral impermissibility of altruistic self-sacrifice. Whether others agree that this approach allays the intuitional conflict between BAS and BOF is a story for another day. For now, I simply want to pave the way for an alternative solution-one I think Thomson might presumably endorse.

\section{§3: Self-Defense and Switching Vantage Points}

All of the work on the trolley problem has focused on what the respective bystanders can do to the strangers-kill the five, kill the one, save the five, etc. From the outset, I want to shift the vantage point from which we have been viewing BAS and BOF. Rather than looking at the two cases from the perspective of the bystanders-and what it is permissible (or impermissible) for them to do-I want to examine them instead from the 
point of view of the individuals whose lives hang in the balance. First, let's reexamine BAS from the point of view of the five people who will be killed if the bystander understandably cannot bring herself to hit the switch. Imagine that one of the five workmen has a gun and it becomes clear that the bystander is not going to be able to bring himself to divert the trolley. Would it be permissible for the workman with the gun to shoot and kill the bystander if doing so was the only way of getting him to fall onto the switch?

In order to figure out how Thomson might answer this question, it is useful to consider three scenarios that she has identified as morally impermissible instances of selfpreservation: ${ }^{15}$

1. Substitution of a bystander: A runaway trolley is going to kill you unless you hit the switch and divert the trolley onto a lone workman-thereby saving yourself $(1991,289)$.

2. Use of a bystander: A runaway trolley is going to kill you unless you shoot a large man on an overpass so that his body will fall onto the tracks-thereby stopping the train and saving you $(1991,290)$.

3. Riding roughshod over a bystander: A runaway trolley is going to kill you and the only escape route is over a bridge that will only hold one person. The bystander who is already on the bridge will fall to her death if you run across the bridge $(1991,290)$.

In BAS, it is not the case that the bystander will kill the five workmen if he cannot bring himself to hit the switch-rather, he will merely allow them to die. That's what distinguishes this case from Foot's Tram Driver. Hence, if we adopt Thomson's permissibility conditions for self-preservation, it is impermissible for the five workmen to

\footnotetext{
${ }^{15}$ There are several important differences between mere self-preservation-which is often unjustified even if it is excusable-and self-defense-which is normally justified. For present purposes, the most important difference is that in the case of self-preservation you sacrifice someone else in order to save yourself whereas self-defense involves defending yourself against someone who poses an immediate threat.
} 
kill the bystander. Moreover, by killing the bystander and diverting the train, the five workmen would also thereby kill the lone workman on the other track-which would be similarly impermissible on Thomson's view. Since neither the innocent bystander at the switch nor the lone workman pose a threat to the lives of the five workmen who will be killed by the trolley, the workmen with the gun cannot kill these two individuals. To do so would be wrong on two fronts according to Thomson as it would involve both a morally impermissible substitution of a bystander with respect to the lone workman and a morally impermissible use of a bystander with respect to the individual at the switch.

This is a very odd line of reasoning for the earlier Thomson to adopt. After all, while she concluded that it was morally permissible for the bystander in BAS to sacrifice the lone workman in order to save the five, Thomson also seemed to be committed to the view that it was nevertheless impermissible for the five workmen-whose lives are in jeopardy - to sacrifice either the bystander at the switch or the lone workman in order to save themselves. It is a strange moral principle indeed that makes it permissible for $\mathrm{X}$ to kill $Y$ in order to save $Z$ that does not at the same time make it permissible for $Z$ to kill $Y$ in order to save himself. Minimally, it is clear that Thomson needed an explanation for why the bystander at the switch could save the five by killing the one when the workmen are morally barred from adopting a similar plan in order to preserve their own lives. ${ }^{16}$

For present purposes, however, I want to set aside this issue in order to raise yet another problem for Thomson's earlier view. Rather than examining BAS from the point of view of either the bystander or the five workmen, I want to look at it from the

\footnotetext{
${ }^{16}$ See Alexander (1993) for an extended discussion of this issue.
} 
perspective of the lone workman instead. Suppose that he has a gun and he suddenly realizes that the bystander has decided to hit the switch. Now imagine that as the bystander reaches for the switch the lone workman has the chance to shoot the bystander to keep him from executing his plan. Would it be morally permissible for the lone workman to do so? Keep in mind that as far as the lone workman is concerned the socalled "innocent bystander" ceases to be a bystander the moment he decides to intervene-especially given how Thomson conceptualizes what it means to be a bystander. ${ }^{17}$ By reaching for and attempting to hit the switch, knowing all the while that doing so will kill the lone workman, the bystander decides to implement a plan that will indirectly violate his general right not to be killed. But as soon as the bystander decides to enter the causal fray, he ceases to be a bystander. And while the intervening bystander may become a hero of sorts to the five workmen he saves, the bystander will at the same time become an aggressor with respect to the lone workman.

Under these circumstances, while the lone workman obviously could allow himself to be sacrificed in the name of the greater good, he is certainly under no moral obligation to do so. And if the lone workman decided instead to defend himself with lethal force, his doing so would be entirely justified. This is a conclusion that Thomson must accept given what she has said elsewhere concerning the permissibility conditions of self-defense. ${ }^{18}$ Compare, for instance, the following three cases:

\footnotetext{
${ }^{17}$ On Thomson's view, "a person is a bystander relative to a particular situation. Suppose $Y$ is in no way causally involved in X's being at risk of death; that seems intuitively to be a sufficient condition for Y's being a bystander to the situation that consists in X's being at risk of death" $(1991,298)$.

${ }^{18}$ On her controversial view, self-defense is permissible even in cases where the threatening party is entirely guilt free with respect to the threat $(1991,286)$.
} 
1. Villainous Aggressor: A driver of a truck is knowingly, intentionally, or maliciously, trying to run you over. You can stop him only by blowing up the truck $(1991,283)$.

2. Innocent Aggressor: The same as Villainous Aggressor except that the driver is not culpable-i.e., he is not knowingly, intentionally, or maliciously trying to run you over (1991, 284).

3. Innocent Threat: A large man falls accidentally from above. If you shift the position of your awning, you can deflect him but he will be killed. If you do not shift the awning, he will fall on you and kill you, but he will not die (1991, 287).

Thomson believes that if you find yourself in a situation such that if you do not kill someone else they will kill you instead, you are justified in killing them first regardless of whether they are trying to kill you knowingly, intentionally, or maliciously. As she says, "once we agree that he is about to violate your right-and that you can prevent this only by killing him -it seems right to conclude that he no longer has a right that you not kill him" (1991, 301).

This remark reveals a key feature of Thomson's position for it makes it clear that she believes that whenever someone threatens to violate your general right not to be killed, he thereby gives up his own right not to be killed-regardless of whether he is at fault for the violation. For instance, if you threaten my life-whether it be intentional or not-and I permissibly defend myself in return, you can't then use self-defense as grounds for attacking me a second time. On Thomson's view, you forfeited your right to self-defense when you threatened my life in the first place. So, while you may understandably try to preserve your own life-especially if you are not intentionally 
posing a threat to my life-your doing so would nevertheless be morally impermissible given the circumstances.

If we adopt this kind of forfeiture account of self-defense, then (a) the lone workman would have the right to defend himself against the bystander, and (b) the bystander would not have the right to defend himself in return. After all, the bystander in BAS surely falls somewhere between a villainous aggressor and an innocent aggressor given that he knowingly decides to implement a plan that will (indirectly) violate the lone workman's general right not to be killed. Hence, the lone workman would certainly be well within his right if he chose to defend himself. In this respect, BAS is much more similar to BOF than commentators have acknowledged. For if the large man turned around just in time to realize what the bystander was intending to do-namely, send him plummeting to his death-he, too, would surely be justified in killing the bystander in self-defense if doing so was the only way to prevent being pushed over the rail himself.

If what I have said so far is roughly correct, then the lone workman and the large man have the same status with respect to self-defense. In both BAS and BOF, the bystanders give up their causal and moral neutrality in deciding to inject themselves into the situation. They thereby also forfeit their respective rights not to be killed. Consequently, both the lone workman and the large man will be justified in using lethal force in defending themselves against the bystanders-turned-aggressors. But this just reveals the tension that exists between what Thomson originally said about BAS and what she says elsewhere about self-defense. Keep in mind that on her view $X$ is justified in killing $Y$ in self-defense if and only if $Y$ will otherwise violate $X$ 's general right to life. Hence, 
the lone workman in BAS would be justified if he shot and killed the bystander if it became clear that he was going to divert the trolley.

Now imagine that it is clear to the bystander in BAS that if he reaches for the switch the lone workman will kill him before he is able to execute his plan. Under these circumstances, trying to implement the plan of killing the one in order to save the five is tantamount to self-sacrifice since the bystander will be killed before his hand ever reaches the switch. Moreover, even if the bystander had a gun of his own, it would not be permissible for him to shoot the lone workman in self-defense for he has forfeited his own right to life-and hence his right to self-defense-by threatening the lone workman in the first place. By my lights, it would be puzzling if it were both permissible for the bystander to hit the switch and impermissible for him to defend himself against the lone workmen who (permissibly) tries to prevent him from doing so.

This puzzlement is further magnified when we consider that by trying to divert the trolley, the bystander would bring about the following three consequences: (a) the lone workman-who would have never been in danger in the first place but not for bystander-permissibly kills the bystander in self-defense, (b) the bystander would suffer a fruitless death, and $(c)$ the five workmen meet the same fate they would have met had the bystander not been at the switch. Minimally, I believe that this curious state of affairs shows that more work remains to be done by those who want to maintain that it is permissible for the bystander to kill the lone workman in BAS but that it is impermissible to kill the large man in BOF. At a minimum, given that the lone workman in BAS has the 
right to self-defense, this suggests that it is impermissible for the bystander to hit the switch after all.

Keep in mind that on most accounts of self-defense, when someone is justified in using self-defense, this flows from the fact that his rights have been violated, that someone is culpable for violating his rights, and that it is unjust that his rights have been violated, etc. ${ }^{19}$ That is, it is the impermissibility of the rights violation that triggers the justification of self-defense (as opposed to an excused act of impermissible selfpreservation under duress). If this is correct and if I am right that the lone workman in BAS would clearly have a legitimate claim to self-defense, then it follows that it is impermissible for the bystander to hit the switch. The same holds in the case of BOF and Short Supply Kill. By switching the vantage point from the bystanders to their potential victims, we find that the victims all have the right to defend themselves (with lethal force if need be). Just as the large man on the footbridge may struggle to avoid being thrown to his death, the lone workmen in BAS and the patient in Short Supply Kill can take active measures to prevent being sacrificed in the name of the greater good. This unwillingness to be sacrificed is not just their prerogative, it's their right. This suggests that while selfsacrifice is permissible (even laudable), sacrificing others in the name of the greater good is problematic. Thomson and Foot were ultimately right-negative duties are weightier than positive duties. To the extent this is the case, then the trolley problem admits of a solution. It turns out we were wrong to think there were conflicting intuitions that needed to be explained (or explained away).

\footnotetext{
${ }^{19}$ For a review of the recent work on self-defense-including Thomson's-see Doggett (2011).
} 
Notice that this self-defense based strategy-grounded in switching vantage points to focus on victim relations-applies to all of the cases we've discussed. In Tram Driver, given that the driver will kill either the five or the one, he impermissibly violates their respective rights. Why, then, is it permissible for the driver to switch the tram to kill the one in order to save the five? To the extent that he will impermissibly kill someone no matter what he does, he is justified in minimizing the number of people he impermissibly kills. So, while all of the victims have the right to self-defense, the driver can permissibly minimize the number of victims whose rights he violates since someone's rights simply must be violated. In Short Supply Passive, on other hand, no one's rights are violated. The lone patient doesn't have a legitimate claim to self-defense because the doctor doesn't impermissibly violate his rights. In this case, we can let one die or let five die. While the permissibility conditions are different from Tram Driver, the numbers play out the same way. In each case, sacrificing one in order to save five is permissible. In the case of Tram Driver, the driver must violate a negative duty with respect to the five or with respect to the one. Given that a negative duty will be violated either way, minimizing the number of failed negative duties is permissible. In the case of Short Supply Passive, the doctor must violate a positive duty with respect to the five or with respect to the one. Given that a positive duty will be violated either way, minimizing the number of failed positive duties is permissible. However, when it comes to BAS, BOF, and Shot Supply Kill, what we find are negative duties pitted against positive duties. Given that the violation of negative duties violates the rights of the victims and triggers the right to self-defense, these violations are impermissible, our initial intuitions notwithstanding. The 
asymmetrical nature of BAS in terms of negative duties and positive duties coupled with the asymmetrical triggering of the right to self-defense suggests that, contrary to the received wisdom, it is impermissible to turn the trolley. In this way, the intuitional array of the trolley problem is thereby resolved.

\section{CONCLUSION}

In this paper, I first surveyed the history of the trolley problem from Philipa Foot to Judith Jarvis Thomson. I then canvassed Thomson's earlier attempts to solve the problem before discussing her more recent about-face. Because I found her latest solution (or attempted dissolution) to be problematic, I revisited Thomson's earlier work on self-defense in an effort to find an alternative route to a solution. By switching the vantage point from the actors to the victims, I tried to reveal an element of the cases that has hitherto escaped notice. On my view, to the extent that the victims being sacrificed have a legitimate claim to self-defense, this suggests that their being sacrificed in the name of the greater good is impermissible after all. So, while it would be heroic if they engaged in altruistic selfsacrifice, it is well within their rights to resist being sacrificed. If I am right about this, it suggests that negative rights are weightier than positive rights-much as Thomson herself came to believe. If this is right, then the trolley problem was much ado about nothing. The entire enterprise was predicated on the mistaken belief that it is permissible for the bystander to kill the one in order to save the five. Once that case is seen aright, the rest of our intuitions fall into their proper place.

\section{REFERENCES}


Alexander, Larry. 1993. Self-Defense, justification, and excuse. Philosophy and Public Affairs Vol. 22 (1): 53-66.

Bentham, Jeremy. 1780/1996. The Collected Works of Jeremy Bentham: An Introduction to the Principles of Morals and Legislation. Eds. Burns, J.H., \& Hart, H.L.A. New York: Oxford University Press.

Di Nucci, Ezio. 2013. Self-sacrifice and the trolley problem. Philosophical Psychology 26(5): 662-672.

Doggett, Tyler. 2011. Recent work on the ethics of self-defense. Philosophy Compass 6(4), 220-233.

Edmonds, David. (2013). Would You Kill the Fat Man? The Trolley Problem and What Your Answer Tells Us About Right and Wrong. Princeton, NJ: Princeton University Press.

Foot, Philipa. 1967. The problem of abortion and the doctrine of double effect. Oxford Review 5: 1-7.

Fried, Barbara. 2012. What does matter? The case for killing the trolley problem (or letting it die). The Philosophical Quarterly 62(248): 505-525.

Friedman, Alexander. 2002. Minimizing Harm: Three Problems in Moral Theory. Unpublished doctoral dissertation. Department of Linguistics and Philosophy, Massachusetts Institute of Technology.

Hauser, Marc. 2006. Moral Minds: How Nature Designed Our Universal Sense of Right and Wrong. New York: Ecco Publishing.

Huebner, Bryce, \& Marc Hauser. 2011. Moral judgments about altruistic self-sacrifice: When philosophical and folk intuitions clash. Philosophical Psychology 24: 73-94.

Hurka, Tom. 2016. Trolleys and permissible harm. In Kamm, F. The Trolley Problem Mysteries. New York: Oxford University Press: 135-150.

Salmond, John William Sir. 1913. Jurisprudence. London: Stevens and Haynes.

Thomson, Judith Jarvis. 1976. Killing, letting die, and the trolley problem. The Monist, 59(2): 204-217.

. 1985. The trolley problem. The Yale Law Journal 94(6): 1395-1415.

1990. The Realm of Rights. Cambridge, MA: Harvard University Press.

1991. Self-defense. Philosophy and Public Affairs 20(4): 283-310. 
2008. Turning the trolley. Philosophy \& Public Affairs 36(4): 359-374.

. 2016. Kamm on the trolley problems. In Francis Kamm, The Trolley Problem Mysteries. New York: Oxford University Press: 113-134.

Wood, Allan. 2011. Humanity as an end in itself. In Derek Parfitt, On What Matters, Vol. 2. New York: Oxford University Press: 58-82. 